\title{
BUDIDAYA UDANG WINDU (Penaeus monodon) SISTEM SEMI-INTENSIF PADA TAMBAK TANAH SULFAT MASAM
}

\author{
Erna Ratnawati*) \\ *) Peneliti pada Balai Riset Perikanan Budidaya Air Payau, Maros
}

\begin{abstract}
ABSTRAK
Tanah sulfat masam adalah nama umum yang diberikan pada tanah yang mengandung senyawa sulfida atau pirit $\left(\mathrm{FeS}_{2}\right)$. Apabila tanah sulfat masam digali untuk dikonversi menjadi tambak atau tambak diperdalam, akan menyebabkan pirit teroksidasi dan menjadi larut selanjutnya dapat menyebabkan penurunan $\mathrm{pH}$ tanah dan meningkatkan kelarutan unsur-unsur toksik seperti besi dan aluminium. Akibatnya produktivitas tambak rendah atau bahkan tidak berproduksi. Oleh karena itu, untuk memberdayakan tambak tanah sulfat masam diperlukan upaya perbaikan terlebih dahulu sebelum digunakan untuk budidaya tambak. Kegiatan utama yang perlu dilakukan dalam usaha budidaya udang windu (Penaeus monodon) di tambak tanah sulfat masam adalah remediasi tambak. Budidaya udang windu dengan pola semi-intensif di tambak tanah sulfat masam yang terlebih dahulu diremediasi dapat mencapai sintasan 57,46\%dengan padat penebaran 80.000 ekor/ha. Hal ini tidak jauh berbeda dengan sintasan pada budidaya udang vanamei pada tambak tanah mineral pola tradisional plus yaitu 60\%-70\% dengan padat penebaran yang sama. Dari hasil yang dicapai ini, menandakan bahwa budidaya pada tambak tanah sulfat masam memberi harapan bagi pembudidaya udang apabila dilakukan pengelolaan tanah tambak yang tepat.
\end{abstract}

KATA KUNCl: udang windu, tambak, tanah sulfat masam, semi-intensif

\section{PENDAHULUAN}

Dalam program Revitalisasi Pertanian, Perikanan dan Kehutanan yang dicanangkan oleh Presiden Republik Indonesia pada tanggal 11 Juni 2005 telah ditetapkan udang termasuk udang windu (Penaeus monodon) untuk dikembangkan di tambak (Anonim, 2005). Udang windu atau udang sitto dan juga dikenal dengan udang bago masih merupakan primadona andalan dari sektor perikanan di Indonesia karena mempunyai harga yang cukup tinggi dan dapat menembus pasaran dunia. Permintaan udang ini dari tahun ke tahun terus meningkat sedangkan produksi yang dihasilkan belum mencukupi kebutuhan dunia sehingga upaya peningkatan produksi perlu mendapat perhatian. Berdasarkan Anonim (2006), bahwa permintaan udang di pasar internasional semakin meningkat yaitu pada tahun 2005 sebesar 294,654 ton sedangkan produksi hanya 232,43 ton.

Dalam rangka meningkatkan produksi udang sebagai sumber devisa negara dan melihat potensi lahan pertambakan yang banyak digunakan oleh pembudidaya, maka perlu dilakukan suatu terobosan baru yaitu dengan mengubah sistem budidaya tambak udang sistem ekstensif menjadi semi-intensif. Salah satu ciri dari budidaya semi-intensif adalah adanya pakan tambahan, karena untuk hidup dan tumbuh udang memerlukan pakan yang cukup kuantitas maupun kualitasnya. Berdasarkan padat penebaran, sistem ekstensif (tradisional) menggunakan padat penebaran 0,1--1,0 ekor $/ \mathrm{m}^{2}$, semi-intensif (madya) 3--10 ekor/m² dan intensif (maju) 15--40 ekor $/ \mathrm{m}^{2}$ atau lebih (Mujiman \& Suyanto, 1997).

Tanah sulfat masam adalah tanah yang mengandung pirit $\left(\mathrm{FeS}_{2}\right)$, apabila teroksidasi dapat menurunkan $\mathrm{pH}$ tanah dan meningkatkan kelarutan unsur-unsur toksik. Bila kondisi ini tidak diperbaiki secara tepat, produktivitas tambak tanah sulfat masam sangat rendah. Potensi tanah sulfat masam secara nasional sebesar 6,4 juta hektar. Tetapi diperkirakan yang berasosiasi dengan tanah salin di wilayah pesisir sekitar 2,4 juta hektar. Sebagian dari potensi lahan ini telah dikonversi menjadi tambak. Diperkirakan 60\%(200.000 ha) dari tambak yang ada (360.000 ha) adalah berasosiasi dengan tanah sulfat masam (Mustafa et al., 2007a). Tingkat produktivitasnya yang sangat rendah bahkan sebagian masih dalam kondisi terlantar dan belum dikelola secara tepat. Status pembudidaya tambak sebagian besar berada pada tahap kepemilikan lahan dan melakukan kegiatan budidaya tambak sangat sederhana. Hal ini disebabkan karena keterbatasan pengetahuan dan keterampilan serta modal yang dimiliki, selain itu teknologi budidaya tambak yang berasosiasi dengan tanah sulfat masam belum bisa dikuasai oleh pembudidaya. Tanah sulfat masam yang tidak dikelola 
dengan baik dapat menyebabkan udang tidak dapat tumbuh dengan baik, mudah diserang penyakit, mortalitas tinggi dan jasad pakan tidak dapat tumbuh dengan baik, sehingga produktivitas tambak udang rendah (Mustafa \& Sammut, 2007).

Tulisan ini bertujuan untuk memberikan gambaran budidaya udang windu secara semi-intensif pada lahan sulfat masam.

\section{LANGKAH-LANGKAH OPERASIONAL}

\section{Persiapan Tambak}

Pelaksanaan suatu kegiatan budidaya udang di tambak memerlukan syarat khusus yang sesuai dengan sifat dan kebiasaan udang windu. Jenis kegiatan budidaya udang windu di tambak antara lain persiapan atau pengolahan tanah dasar, penebaran benur, pemeliharaan, dan panen serta pascapanen (Buwono, 1993).

Langkah langkah dalam persiapan tambak antara lain: a) Remediasi; b) Pemberantasan hama; c) Pengapuran; d) Pemupukan; e) Pengisian air.

\section{Remediasi}

Menurut Tarunamulia et al. (2006), tanah sulfat masam jika teroksidasi dapat menyebabkan berbagai masalah produksi antara lain: 1) laju pertumbuhan ikan dan udang yang rendah; 2) kematian massal pada ikan dan udang; 3 ) adanya partikel besi pada insang; 4) tingkat kepadatan yang rendah dari alga yang bermanfaat; 5) kebutuhan kapur dan pupuk yang tinggi; 6) kualitas fisik tanah yang rendah; 7) toksisitas hydrogen sulfide $\left(\mathrm{H}_{2} \mathrm{~S}\right)$ jika sulfide Fe, $M n$, dan Al tidak terbentuk; 8) suspensi partikel besi dalam air; 9) pH dan alkalinitas air rendah. Oleh karena itu, untuk memberdayakan tambak tanah sulfat masam diperlukan upaya perbaikan terlebih dahulu sebelum digunakan untuk budidaya tambak.

Remediasi adalah suatu aktivitas atau proses atau penambahan suatu material yang dilakukan untuk mengurangi unsur-unsur toksik di tanah atau air tanah. Kata reklamasi dan ameliorasi terkadang digunakan untuk mengganti kata remediasi dalam pengertian yang relatif sama. Prinsip remediasi adalah pengeringan tanah untuk mengoksidasi pirit, perendaman untuk melarutkan dan menetralisir kemasaman atau menurunkan produksi kemasaman lanjut, dan pencucian untuk membuang hasil oksidasi yaitu $\mathrm{H}_{2} \mathrm{SO}_{4}$ (asam sulfat) dan meminimalkan cadangan-cadangan unsur toksik dalam tanah (Mustafa et al., 2006).

Sebelum petakan tambak diremediasi, pematang, pipa pipa pemasukan dan pengeluaran air diperbaiki terutama jika ada bocoran dan perembesan agar pengeringan tanah lebih sempurna. Tanah pelataran tambak dicangkul terlebih dahulu sedalam 0,2--0,3 m agar luas permukaan tanah bertambah sehingga proses oksidasi lebih baik. Pengeringan tanah pelataran tambak dilakukan selama 2 minggu pada keadaan terik matahari sehingga tanah pelataran menjadi retak-retak, tetapi tidak terlalu kering. Cara sederhana untuk mengetahui tingkat kekeringan tanah pelataran yang dikehendaki adalah dengan berjalan di atasnya. Jika tanah yang kita injak turun sedalam 1--2 $\mathrm{cm}$, maka pengeringan dianggap cukup. Selanjutnya petakan tambak diisi air sampai ketinggian 0,4 $\mathrm{m}$ dan dibiarkan terendam selama 3 hari, kemudian air rendaman dibuang dan diisi kembali, dengan air setinggi 0,4 m dan dibiarkan selama 3 hari, kemudian dibuang kembali. Proses remediasi diulangi sebanyak 2--3 kali sampai kondisi tanah menjadi lebih baik. Air rendaman dibuang pada saat surut terendah atau menggunakan bantuan pompa celup agar air yang mengandung unsur-unsur toksik tersebut dapat terbilas sempurna (Mustafa et al., 2006).

Pada saat tanah sulfat masam terjemur, terjadi proses oksidasi pirit dan pada saat perendaman hasil oksidasi akan larut dalam air rendaman, selanjutnya akan terbuang bersama air buangan. Dengan melakukan proses tersebut berulang kali, maka unsur-unsur toksik seperti Al, $\mathrm{Mn}$, dan Fe yang juga merupakan unsur penyebab kemasaman tanah dapat berkurang. Sebagai akibatnya terjadi peningkatan $\mathrm{pH}$ tanah mendekati $\mathrm{pH}$ netral $\mathrm{pH}$ sekitar 6) dan penurunan kandungan unsur-unsur toksik. Dengan kondisi demikian pupuk yang diberikan akan lebih efisien, sebab unsur hara menjadi lebih tersedia untuk pertumbuhan makanan alami seperti plankton dan klekap. Berkurangnya unsur-unsur toksik dapat meningkatkan

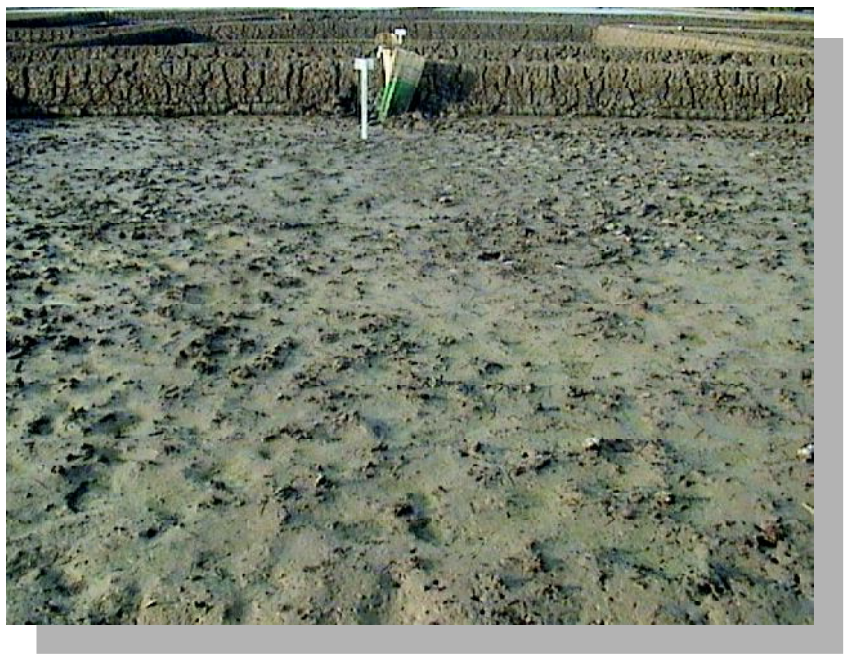

Gambar 1. Pengeringan tanah dasar tambak tanah sulfat masam dalam proses remediasi (Foto: Akhmad Mustafa, BRPBAP Maros) 
sintasan dan pertumbuhan organisme yang dibudidayakan. Dengan melimpahnya makanan alami dan kualitas lingkungan yang lebih baik berdampak pada peningkatan produktivitas tambak, terutama tambak yang dikelola dengan teknologi tradisional (ekstensif) dan semiintensif.

\section{Pemberantasan hama}

Faktor lain yang ikut menentukan keberhasilan budidaya udang di tambak adalah keberhasilan dalam usaha pengendalian/pemberantasan hama di dalam tambak.

Dalam pemberantasan hama, pestisida anorganik yg digunakan adalah saponin dengan dosis $20 \mathrm{mg} / \mathrm{L}$. Keuntungan jenis racun ini karena dapat menjadi pupuk setelah daya racunnya hilang (ampasnya). Oleh karena itu, pengendalian hama di tambak sebaiknya dilakukan dengan mempergunakan cara mekanis dan pestisida organik (pestisida nabati). Apabila dengan mempergunakan cara tersebut belum memberikan hasil yang diharapkan, maka sebagai langkah terakhir barulah mempergunakan pestisida anorganik yang memiliki residu yang sangat rendah.

\section{Pengapuran}

Permasalahan utama pada tambak tanah sulfat masam antara lain adalah: pH rendah (7 3,5); kurang tersedia unsur fosfor $(\mathrm{P})$, kalsium (Ca), dan magnesium $(\mathrm{Mg})$; kandungan unsur molibdium (Mo) dan besi (Fe) sering berlebihan sehingga dapat meracuni organisme; serta kelarutan aluminium (Al) sering tinggi sehingga merupakan penghambat ketersediaan P. Penambahan pupuk, terutama yang mengandung $P$ sering tidak bermanfaat pada tanah masam ini bila unsur-unsur toksik seperti Al, Fe, dan Mn tidak diatasi. Untuk mengatasi hal ini biasanya pengapuran menjadi alternatif yang paling banyak digunakan. Pengapuran adalah salah satu bentuk dari remediasi selain pengoksidasian dan pembilasan tanah.

Jenis kapur yang digunakan pada kegiatan budidaya udang tradisional plus ini adalah kapur dolomite (Ca Mg $\left(\mathrm{CO}_{3}\right)_{2}$, karena kapur ini memiliki pengaruh yang lebih lama, mudah diperoleh, meninggalkan residu dan kecepatan reaksinya lebih lambat, serta juga mengandung Mg selain Ca.

Pengapuran yang dilakukan dibagi atas 2 tahap yaitu pengapuran dasar dan pengapuran susulan. Pengapuran dasar dilakukan setelah pengeringan tambak dengan dosis $1.000-1.875 \mathrm{~kg} / \mathrm{ha}$ yang ditebar secara merata ke permukaan tanah dasar tambak, tergantung $\mathrm{pH}$ tanah dasar tambak.

\section{Pemupukan}

Pemupukan dimaksudkan untuk meningkatkan kesuburan tanah, yang mengakibatkan suburnya makanan alami bagi udang windu, terutama berupa klekap, lumut yang tumbuh pada pelataran tambak maupun yang hidup sebagai plankton. Hal ini mengingat udang akan cepat besar bilamana di dalam tambak tersedia makanan yang bermutu dan dalam jumlah yang cukup (Soetomo, 2000). Pupuk yang mengandung fosfor seperti TSP atau SP-36 sebaiknya diberikan dalam bentuk larutan (Gambar 2) agar fosfor yang ada dalam pupuk tidak berkontak langsung dengan tanah yang dapat menyebabkan fosfat terikat. Pupuk yang digunakan adalah urea dan TSP masingmasing 50 dan 100 kg/ha yang diaplikasikan secara merata di atas permukaan tambak. Air yang digunakan untuk melarutkan pupuk tersebut sebanyak 100 liter. Dosis pupuk TSP diaplikasi lebih tinggi daripada dosis urea, sebab kandungan fosfat tersedia tanah sulfat masam relatif rendah. Pemupukan dasar dilakukan jika kualitas air sudah dianggap layak untuk kehidupan udang. Untuk melakukan pemupukan dasar, dasar tambak diisi air setinggi 0,05 $\mathrm{m}$ dan selanjutnya dibiarkan menguap. Setelah 2--3 hari air dimasukkan kembali secara bertahap sampai ketinggian $0,15 \mathrm{~m}$ sesuai metode air dangkal untuk pertumbuhan pakan alami (Ilyas et al., 1987).

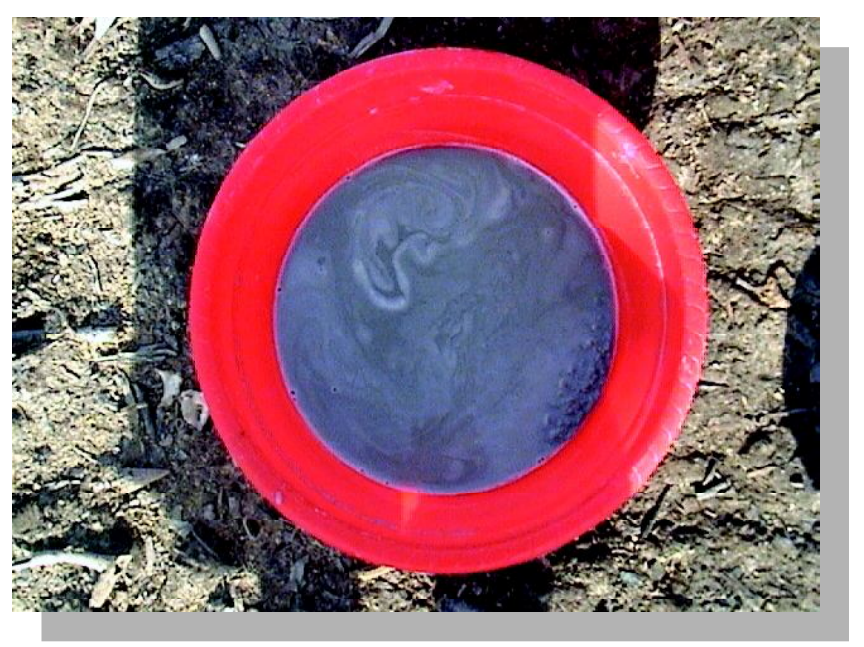

Gambar 2. Pupuk SP-36 yang dilarutkan terlebih dahulu untuk aplikasi di tambak tanah sulfat masam (Foto: Akhmad Mustafa, BRPBAP Maros)

\section{Pengisian air}

Setelah pengolahan tanah dasar selesai kegiatan selanjutnya adalah pengisian air kedalam tambak dengan ketinggian air 0,6--1,0 m; kemudian dibiarkan selama 10--14 hari sampai pakan alami tumbuh dan tambak siap ditebari. 


\section{Penebaran}

Dalam budidaya udang windu secara semi-intensif, penebaran benur sebaiknya dilakukan 2 minggu setelah pemupukan dasar, yang mana pada saat tersebut makanan alami tumbuh dengan baik dan kualitas air sudah layak bagi kehidupan udang.

Benih udang ditebar kedalam petakan pada pagi hari sekitar pukul 06.00--07.00. Sebelum benur ditebar, benur diaklimatisasi guna mencegah terjadinya stres. Bobot awal benur $0,08 \mathrm{~g}$ dengan padat penebaran adalah $8 \mathrm{ekor} / \mathrm{m}^{2}$.

\section{Pemeliharaan}

Dalam usaha mempertahankan kehidupan dan memacu pertumbuhan udang diperlukan pemenuhan segala kebutuhan yang sesuai dengan sifat biologis udang windu dan adanya lingkungan yang menunjang sehingga udang windu merasa aman, tenang, dan berkecukupan dalam hidupnya (Soetomo, 2000).

Selama pemeliharaan dilakukan penggantian air sebesar $40 \%$ dari volume pada saat pasang tinggi dan pemupukan susulan sebesar 10\%dari pupuk dasar setiap 10 hari. Dosis pakan yang diaplikasikan adalah 2\%-10\% bobot badan/hari dengan frekuensi pemberian 2 kali/ hari. Pemberian pakan buatan mengalami perubahan berdasarkan hasil penimbangan udang setiap 2 minggu. Jadwal pemberian pakan adalah pagi hari (pukul 07.00) dan sore hari (pukul 17.00). Jumlah pakan yang diberikan lebih banyak pada sore hari karena sifat udang aktif mencari makan pada malam hari.

Kualitas air yang layak untuk pembesaran udang windu mempunyai optimal 15--25 ppt, udang akan tumbuh lebih cepat pada salinitas 5--10 ppt, tetapi lebih sensitif terhadap penyakit (Buwono, 1993). Kisaran pH terbaik bagi kehidupan dan pertumbuhan udang windu adalah antara 7,5--8,5. Alkalinitas juga penting dalam kegiatan budidaya karena dapat menunjang kelangsungan hidup organisme yang dibudidayakan. Alkanitas yang layak untuk udang windu lebih besar $80 \mathrm{mg} / \mathrm{L}$ (Chanratchakool et al., 1995). Kualitas air mudah berubah pada tambak tanah sulfat masam, sehingga pemantauan kualitas air penting dilakukan terutama setelah turun hujan (Gambar 3).

\section{Panen}

Setelah pemeliharaan udang selama kurang lebih 3 bulan maka dilakukan pemanenan. Peralatan yang perlu disiapkan adalah jaring yang dipasang pada pintu air, jala lempar, keranjang panen, baskom, ember, dan steroform. Teknik pemanenan dilakukan dengan menurunkan volume air secara gravitasi dan pompa, bersamaan dengan itu dilakukan penangkapan udang dengan jala. Produksi yang

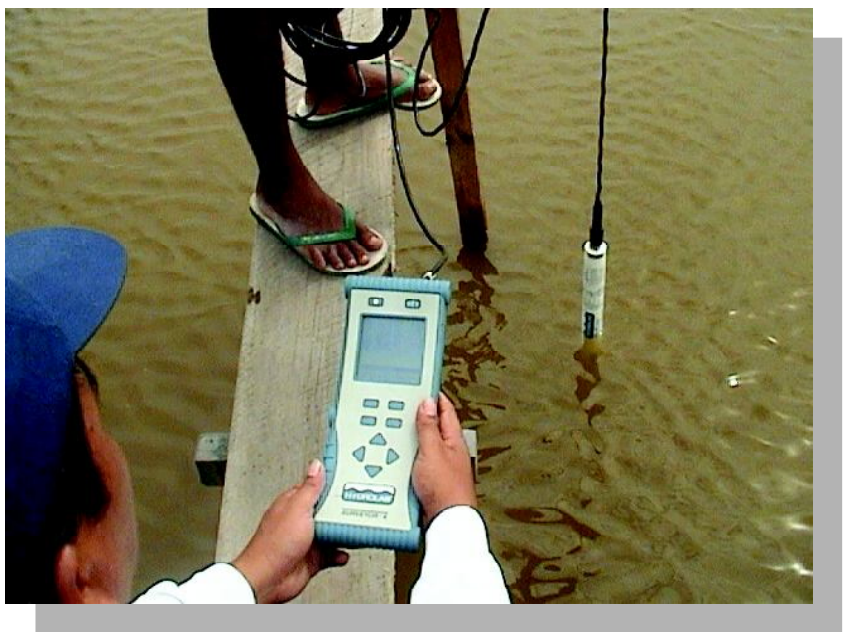

Gambar 3. Pemantauan kualitas air yang perlu selama budidaya udang windu di tambak tanah sulfat masam (Foto: Akhmad Mustafa, BRPBAP Maros)

diperoleh pada tambak tanah sulfat masam yang terlebih dahulu diremediasi tanah dasarnya (Gambar 4), dengan padat penebaran 8 ekor $/ \mathrm{m}^{2}$ adalah $828,25 \mathrm{~kg} / \mathrm{ha}$ sedang pada tambak tanah sulfat masam yang tidak diremediasi, produksinya $213,5 \mathrm{~kg} / \mathrm{ha}$ (Tabel 1 ).

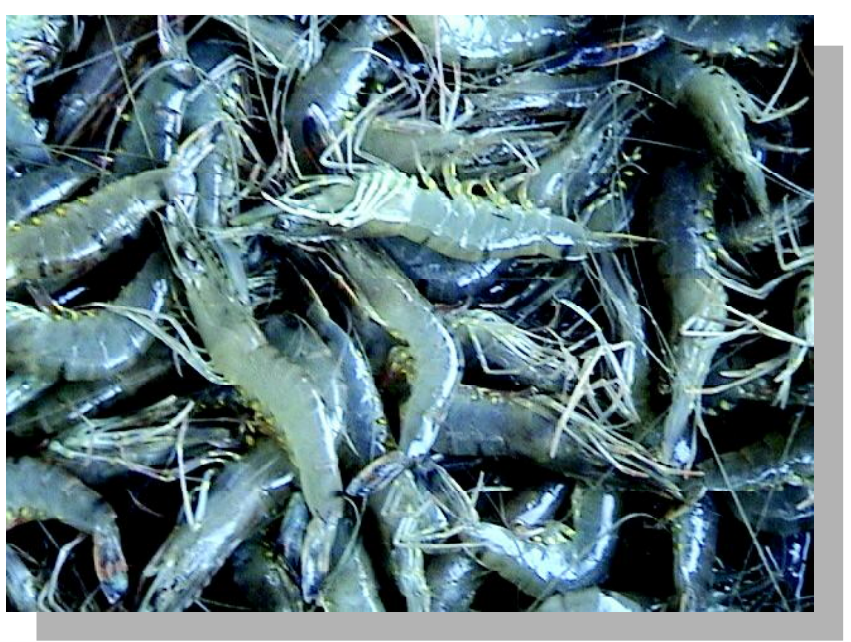

Gambar 4. Udang windu yang dipanen dari tambak tanah sulfat masam yang tanah dasarnya terlebih dahulu diremediasi (Foto: Akhmad Mustafa, BRPBAP Maros)

\section{PENUTUP}

Dalam usaha budidaya udang windu sistem intensif di tambak tanah sulfat masam remediasi merupakan kunci keberhasilan. Produksi budidaya udang windu (Penaeus monodon) pada tanah dasar yang diremediasi jauh lebih besar dibandingkan dengan tanpa remediasi, sintasan 
Tabel 1. Produksi udang windu pada tambak tanah sulfat masam yang tanah dasarnya diremediasi dan tanpa diremediasi

\begin{tabular}{lcc}
\hline \multirow{2}{*}{\multicolumn{1}{c}{ Peubah }} & \multicolumn{2}{c}{ Remediasi tanah dasar } \\
\cline { 2 - 3 } & Tanpa & Dengan \\
\hline Padat penebaran (ekor $/ \mathrm{m}^{2}$ ) & 8 & 8 \\
Bobot awal $(\mathrm{g})$ & 0,08 & 0,08 \\
Lama pemeliharaan (hari) & 98 & 98 \\
Bobot akhir (g) & 9,7 & 18,02 \\
Sintasan (\% & 27,52 & 57,46 \\
Produksi (kg/ha) & 213,5 & 828,25 \\
Rasio konversi pakan & 2,32 & 1,23 \\
\hline
\end{tabular}

Sumber: Mustafa et al. (2006)

udang windu bisa meningkat $100 \%$ dari $27,52 \%$ menjadi $57,46 \%$ Dengan padat penebaran 80.000 ekor/ha dapat memberikan produksi $828,25 \mathrm{~kg} / \mathrm{ha} /$ musim tanam setelah dipelihara selama 98 hari.

\section{DAFTAR PUSTAKA}

Anonim. 2005. Revitalisasi Perikanan Budidaya 2006 2009. Departemen Kelautan dan Perikanan, Jakarta. $275 \mathrm{pp}$.

Anonim. 2006. Udang masih prospek di Jepang. Warta Pasar Ikan, edisi Mei 2006, Jakarta. p. 2-6.

Buwono, I.D. 1993. Tambak Udang Windu Sistem Pengelolaan Berpola Intensif. Kanisius, Yogyakarta. $155 \mathrm{pp}$.

Chanratchakool, P., J.F. Turnbull, S. Funge-Smith, and C. Limsuwan. 1995. Health Management in Shrimp
Ponds. Second edition. Aquatic Animal Health Research Institute, Department of Fisheries, Kasetsart University Campus, Bangkok. 111 pp.

Ilyas, S., A. Poernomo, R. Arifuddin, T. Danlay, A. Ismail, S. Koesoemadinata, I.N.S. Rabegnator, dan S. Soepriyadi. 1987. Petunjuk Teknis bagi Pengoperasian Unit Usaha Pembesaran Udang Windu. Pusat Penelitian dan Pengembangan Perikanan, Jakarta, 99 pp.

Mujiman, A. dan S.R. Suyanto. 1997. Budidaya Udang Windu. Penebar Swadaya, Jakarta. 211 pp.

Mustafa, A., Tarunamulia, dan J. Sammut. 2006. Remediasi tambak tanah sulfat masam. Brosur. Balai Riset Perikanan Budidaya Air Payau, Maros, 2 pp.

Mustafa, A. and J. Sammut. 2007. Effect of different remediation techniques and dosages of phosphorus fertilizer on soil quality and klekap production in acid sulfate soil affected aquaculture ponds. Indonesian Aquaculture Journal. 2(2): 141- 157.

Mustafa, A., M. Paena, Hasnawi, A.M. Pirzan, E. Ratna, A.M. Tangko, R. Sabang, Sutrisyani, Darsono, Kamariah, Rahmiyah, dan Haking. 2007a. Validasi dan Kesesuaian Lahan Tambak di Kab. Luwu Utara Propinsi Sulawesi Selatan. Laporan Teknis Balai Riset Perikanan Budidaya Air Payau, Maros. 123 pp.

Soetomo, H.A. 2000. Teknik Budidaya Udang Windu. Sinar Baru Algensindo, Bandung. 180 pp.

Tarunamulia, J. Sammut, dan A. Mustafa. 2006. Identifikasi dan pengelolaan tanah sulfat masam untuk budidaya udang. Brosur. Balai Riset Perikanan Budidaya Payau, Maros, 2 pp. 